\title{
INITIAL SUCCESSIVE COEFFICIENTS FOR CERTAIN CLASSES OF UNIVALENT FUNCTIONS INVOLVING THE EXPONENTIAL FUNCTION
}

\section{Lei Shi, Zhi-GAng WANG*, REn-Li Su And MuHAmmad ARIF}

\begin{abstract}
Let $\mathscr{S}$ denote the family of all functions that are analytic and univalent in the unit disk $\mathbb{D}:=\{z:|z|<1\}$ and satisfy $f(0)=f^{\prime}(0)-1=0$. In the present paper, we consider certain subclasses of univalent functions associated with the exponential function, and obtain the sharp upper bounds on the initial coefficients and the difference of initial successive coefficients for functions belonging to these classes.
\end{abstract}

Mathematics subject classification (2010): Primary 30C45; Secondary 30C80.

Keywords and phrases: Univalent function, exponential function, successive coefficient.

\section{REFERENCES}

[1] F. Carlson, Sur les coefficients d'une fonction bornée dans le cercle unité, Ark. Mat. Abst. Fys., 27A No. 1, 8 pp, (1940).

[2] A. W. Goodman, Univalent Functions, Vol. II., Mariner Publishing Co., Inc., Tampa, FL, 1983.

[3] W. K. Hayman, On successive coefficients of univalent functions, J. London Math. Soc. 38 (1963), $228-243$.

[4] S. Kumar, V. RaVichandran AND S. Verma, Initial coefficients of starlike functions with real coefficients, Bull. Iranian Math. Soc. 43 (2017), 1837-1854.

[5] S. Kumar And V. Ravichandran, Subordinations for functions with positive real part, Complex Anal. Oper. Theory 12 (2018), 1179-1191.

[6] Y. LeUnG, Successive coefficients of starlike functions, Bull. London Math. Soc. 10 (1978), 193-196.

[7] M. Li And T. Sugawa, A note on successive coefficients of convex functions, Comput. Methods Funct. Theory 17 (2017), 179-193.

[8] R. J. LIBERA AND E. J. ZŁOTKIEWICZ, Early coefficients of the inverse of a regular convex function, Proc. Amer. Math. Soc. 85 (1982), 225-230.

[9] R. J. LIBERA AND E. J. ZŁOTKIEWICZ, Coefficient bounds for the inverse of a function with derivatives in P, Proc. Amer. Math. Soc. 87 (1983), 251-257.

[10] W. MA AND D. MindA, An internal geometric characterization of strongly starlike functions, Ann. Univ. Mariae Curie-Skłodowska (Sect. A) 45 (1991), 89-97.

[11] R. MENDiRatTA, S. NAGPAL AND V. RAVICHANDRAN, On a subclass of strongly starlike functions associated with exponential function, Bull. Malays. Math. Sci. Soc. 38 (2015), 365-386.

[12] A. NAZ, S. KUmAR AND V. RAVICHANDRAN, Coefficient and radius estimates of starlike functions with positive real part, preprint, arXiv: 1905.05413.

[13] Z.-G. PENG AND M. OBRADOVIĆ, The estimate of the difference of initial successive coefficients of univalent functions, J. Math. Inequal. 13 (2019), 301-314.

[14] D. V. Prokhorov and J. Szynal, Inverse coefficients for $(\alpha, \beta)$-convex functions, Ann. Univ. Mariae Curie-Skodowska (Sect. A) 35 (1981), 125-143.

[15] M. S. Robertson, Univalent functions starlike with respect to a boundary point, J. Math. Anal. Appl. 81 (1981), 327-345.

[16] W. Rogosins KI, On the coefficients of subordinate functions, Proc. Lond. Math. Soc. 48 (1943), $48-82$. 
[17] L. Shi, H. M. SRivastava, M. ARIF, S. Hussain And H. Khan, An investigation of the third Hankel determinant problem for certain subfamilies of univalent functions involving the exponential function, Symmetry 11 (2019), Art. 598.

[18] H. TANG AND G.-T. DENG, Majorization problems for two subclasses of analytic functions connected with the Liu-Owa integral operator and exponential function, J. Inequal. Appl. 2018 (2018): 277.

[19] Z.-G. WANG, H. M. SRIVASTAVA AND S.-M. YuAn, Some basic properties of certain subclasses of meromorphically starlike functions, J. Inequal. Appl. 2014 (2014): 29.

[20] Z. Ye, On successive coefficients of odd univalent functions, Proc. Amer. Math. Soc. 133 (2005), 3355-3360.

[21] Z. YE, On the successive coefficients of close-to-convex functions, J. Math. Anal. Appl. 283 (2003), 689-695.

[22] P. ZAPRAWA, Hankel determinants for univalent functions related to the exponential function, Symmetry 11 (2019), Art. 1211.

[23] H.-Y. Zhang, H. TANG AND X.-M. NiU, Third-order Hankel determinant for certain class of analytic functions related with exponential function, Symmetry 10 (2018), Art. 501. 